\title{
Epidemiology of severe trauma among status Aboriginal Canadians: a population-based study
}

\author{
Shahzeer Karmali, Kevin Laupland, A. Robert Harrop, Christi Findlay, Andrew W. Kirkpatrick, \\ Brent Winston, John Kortbeek, Lindsay Crowshoe, Morad Hameed
}

§ See related article page 1023

Abstract

Background: Aboriginal Canadians are considered to be at increased risk of major trauma. However, population-based studies characterizing the distribution, determinants and outcomes of major trauma in this group are lacking. We sought to measure the impact of ethnicity, as reflected by Aboriginal status, on the incidence of severe trauma and to broadly define the epidemiologic characteristics of severe trauma among status Aboriginal Canadians in a large health region.

Methods: This population-based, observational study involves all adults (people $\geq 16$ years) resident in the Calgary Health Region between Apr. 1, 1999, and Mar. 31, 2002. Stratification of the population into status Aboriginal Canadians and the reference population was performed by Alberta Health and Wellness using an alternate premium arrangement field within the personal health care number. Injury incidence was determined by identifying all injuries with severity scores of 12 or greater in the Alberta Trauma Registry, regional corporate data and the Office of the Medical Examiner.

Results: Aboriginal Canadians were at much higher risk than the reference population in the Calgary Health Region of sustaining severe trauma (257.2 v. 68.8 per 100 000; relative risk [RR] 3.7, 95\% confidence interval [CI] 3.0-4.6). Aboriginal Canadians were found to be at significantly increased risk of injuries resulting from motor vehicle crashes (RR 4.8, 95\% Cl 3.5-6.5), assault (RR 11.1, 95\% Cl 6.2-18.6) and traumatic suicide (RR 3.1, 95\% Cl 1.4-6.1). A trend toward higher median injury severity scores was observed among Aboriginal Canadians (21 v. 18, $p=0.09$ ). Although the case-fatality rate among Aboriginal Canadians was less than half that in the reference population (14/93 [15\%] v. 531/1686 [31\%], $p$ $<0.0001)$, population mortality was almost 2 times greater $(\mathrm{RR}=1.8,95 \% \mathrm{Cl} 1.0-3.0, p=0.046)$.

Interpretation: Severe trauma disproportionately affects Aboriginal Canadians.

CMAJ 2005;172(8):1007-11

T $\mathrm{n}$ Canada, injury is the leading cause of death among people under the age of 45 and the leading cause of potential years of life lost. ${ }^{1}$ Although difficult to quantify, the cost of injury was estimated to be at least $\$ 12.7$ billion in $1998 .^{2}$
Trauma has been known, even in industrialized countries, to disproportionately affect the most marginalized members of society. ${ }^{3}$ Aboriginal Canadians are considered to be particularly at risk, and data showing alarming patterns of trauma mortality in this group are beginning to emerge. Unfortunately, the number of studies looking at injury risk among Aboriginal Canadians is small, ${ }^{4}$ and little attention has been paid to quantifying the risk of nonfatal injury. Better understanding of the nature of trauma risk and outcome among Aboriginal Canadians could lead to more effective prevention and treatment strategies.

In this study, we used a population-based design in an attempt to quantify the impact of injury, both fatal and nonfatal, on the Aboriginal community in a large, heterogeneous Canadian region with over 1 million urban and rural inhabitants. We sought to measure the impact of ethnicity (defined by registered status within the definition of the Indian Act ${ }^{5}$ ) on the incidence of severe trauma and to broadly define the epidemiologic characteristics of severe trauma among status Aboriginal Canadians.

\section{Methods}

The Calgary Health Region is a fully integrated, publicly funded health system that provides virtually all medical and surgical care to residents of the city of Calgary and its surrounding areas. ${ }^{6}$ Three large reserves (Stoney, Siksika and Sarcee [Tsuu Tina]) are located within its boundaries. All adults ( $\geq 16$ years of age) living in the health region between Apr. 1, 1999, and Mar. 31, 2002, formed the study cohort. Denominator data, referring to the entire population of the health region for the exact period of the study, were obtained from the Research Access and Policy Support Unit of Alberta Health and Wellness. This data set categorized residents of the health region with personal health care numbers according to age, sex and ethnicity. Comparison of these data with Canadian census data showed nearly exact correlation.

The term "status Aboriginal" refers to a person who is registered under the Indian Act. ${ }^{5}$ Only people whose personal histories meet criteria specified by this act and who apply to the Government of Canada are eligible for such registration. Provincial health care benefit premiums for people with Aboriginal status and their dependents are paid by Health Canada.

The Alberta personal health care number contains an "alter- 
nate premium arrangement" field, in which this health care coverage plan is specified. By analysis of this field, Alberta Health and Wellness was able to provide us with a proxy for ethnicity. This method of stratification (which was used to define both the composition of the residents of the health region who sustained severe trauma and the composition of the residents of the health region in general) enabled comparison of trauma incidence rates between status Aboriginal Canadians and the reference population, which included all other residents of the health region.

The ethnicities of 343 trauma patients with missing personal health care numbers were determined using their surnames. Of the 93 Aboriginal Canadian trauma patients identified in this study, 9 were identified using this method, which was separately validated using 1000 patients with known personal health care numbers and was found to be $99.9 \%$ specific and $53.8 \%$ sensitive. The use of surnames to determine ethnicity in this small subset of patients may have resulted in an underestimation of the number of Aboriginal Canadian trauma patients.

The Alberta Trauma Registry prospectively collects data on the vast majority of patients in the province who sustain severe, multisystem injury (injury severity score $\geq 12$ ). ${ }^{7}$ The injury severity score, which summarizes the extent of injury at different anatomic sites into a single number (the sum of squares of the grades of injury in each of the 3 most severely injured areas, to a maximum of 75), has been used as a reference point for the evaluation and comparison of trauma outcomes. ${ }^{8}$ An injury severity score of 12 or greater has been associated with multisystem injuries requiring multidisciplinary trauma care and significant resource expenditure. All 23 trauma centres in Canada that provide data to the Major Trauma Dataset of the National Trauma Registry have adopted an injury severity score of 12 or greater to create a working definition of what constitutes major trauma and what justifies registry data collection.
Patients entered in the Calgary component of the Alberta Trauma Registry (mostly through analysis of trauma admissions to the region's single tertiary care trauma referral centre) with addresses within the borders of the Calgary Health Region were identified, and detailed data on the circumstances of their injury, the extent and nature of their injuries, and their outcomes were prospectively extracted. The minority of patients with severe injuries who were inadvertently triaged to and treated at either of the 2 nontrauma referral hospitals within the region were captured through active screening by registry data analysts, as well as by a comprehensive survey of the regional corporate data. Traumatic deaths and their circumstances were identified using the databases of the Office of the Chief Medical Examiner.

This strategy of trauma patient identification - which relied on a streamlined, integrated regional trauma referral system to a single trauma centre, limited alternatives for definitive complex trauma care, and active surveillance of other major hospitals makes it highly unlikely that significant numbers of severely injured patients in the health region were not identified.

Source data were exported and merged. Missing values were not replaced. Medians with interquartile ranges (IQR) were used to describe non-normally distributed variables. Differences in proportions were compared using Fisher's exact test and medians using the Wilcoxon rank-sum test. Overall annual incidence rates were compared using the normal approximation for the comparison of Poisson counts. Overall and category-specific rates of incidence and relative incidence were calculated using the numbers of cases observed in the study as numerator and local population demographic data as denominator data.

The study design received institutional ethics approval from the Calgary Conjoint Health Research Ethics Board. It has been endorsed by the Region 3 Aboriginal Community Health Council.

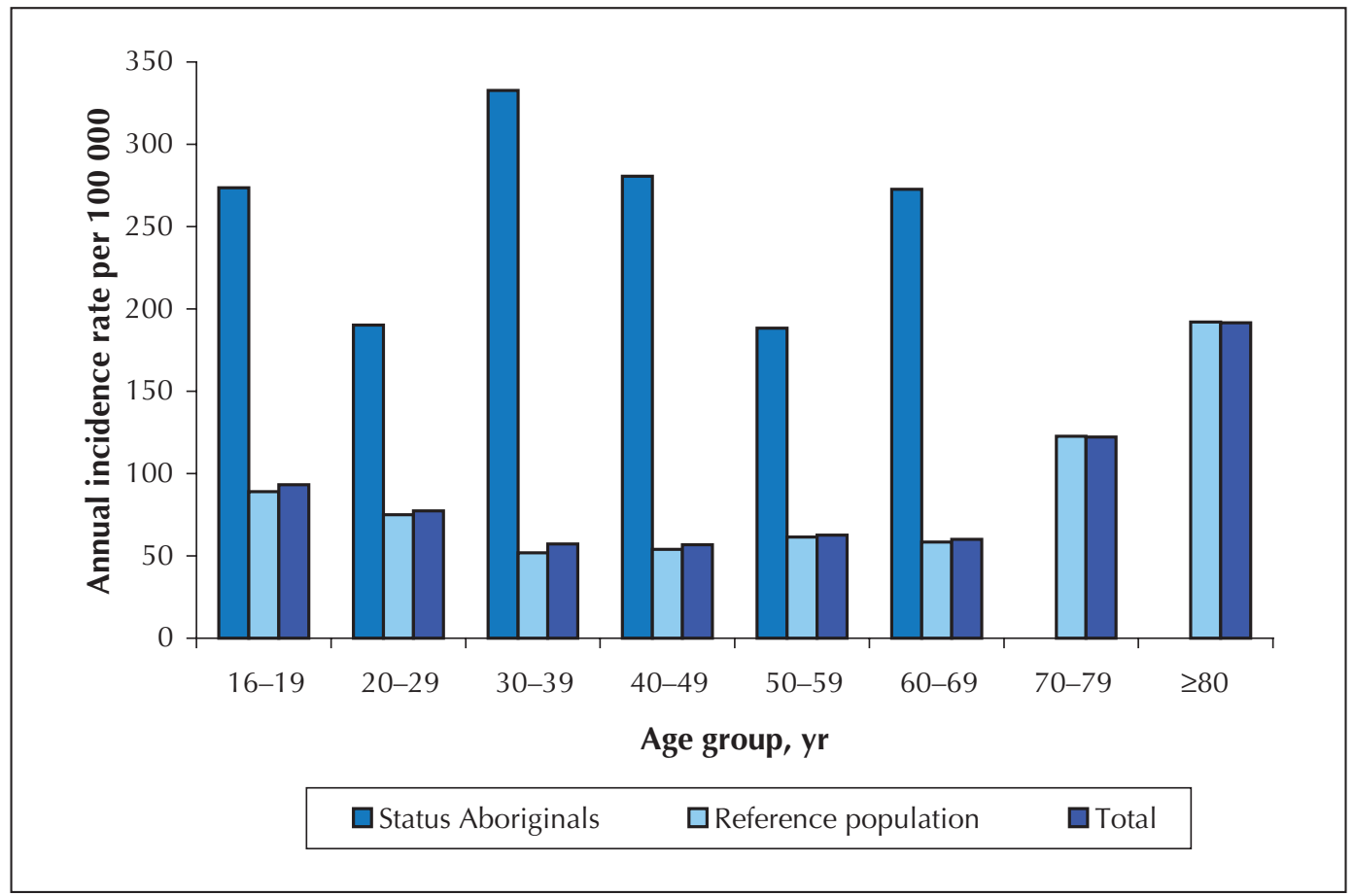

Fig. 1: Age-specific incidence of severe, multisystem injury (injury severity score $\geq 12$ ) in the Calgary Health Region, Calgary (Alta.), 1999-2002. 


\section{Results}

A total of 1779 patients experienced severe trauma during the study period, for an overall annual adult incidence rate of 71.5 per 100000 population (36 155 Aboriginal Canadians and 2452499 people in the reference population were at risk over the 3 years). Six people (2 Aboriginal Canadians) had second discrete episodes of major trauma during the study period, but these second episodes were excluded from further analyses. The incidence of severe trauma among Aboriginal Canadians (93 patients) was nearly 4 times higher (RR 3.7, 95\% CI 3.0-4.6) than that in the reference population (1686 patients), with annual incidence rates of 257.2 and 68.8 per 100000 population respectively. Adjustment for age and sex revealed a similar result (RR 3.6, 95\% CI 3.4-3.8).

Although the median age of the Aboriginal Canadian trauma patients was significantly lower than that of the reference population (36 [IQR 25-42] v. 42 [IQR 28-58] years, $p<$ 0.0001 ), the incidence of severe trauma was higher in the Aboriginal Canadian group in every age category (Fig. 1). Interestingly, Aboriginal Canadians appear to be at highest risk in the fourth and fifth decades of life, when trauma incidence in the reference population is at its lowest. The incidence of major trauma among Aboriginal Canadians was significantly higher for men than for women (418.4 v. 106.9 per 100000 per year; RR 3.9, 95\% CI 2.4-6.8). The risk of major trauma among Aboriginal Canadian women was comparable to that among men in the reference population (Fig. 2).

Most [60 (65\%)] cases of major trauma among Aboriginal Canadians were unintentional, at an incidence rate of 166.0 per 100000 per year. Intentional causes included assault (17 $[18 \%])$, suicide $(9[10 \%])$ and homicide (1 [1\%]), with annual incidence rates of 47.0, 24.9 and 2.8 per 100000 population respectively. Aboriginal Canadians were at higher risk than people in the reference population for unintentional trauma (166.0 v. 53.8 per 100000 per year, RR 3.1, 95\% CI 2.3-4.0), assault (47.0 v. 4.2 per 100000 per year, RR $11.1,95 \%$ CI 6.2-18.6) and traumatic suicide (24.9 v. 7.9 per 100000 per year, RR 3.1, 95\% CI 1.4-6.1). Only for homicide was the difference in risk reversed. Among Aboriginal Canadians, women were more likely than men to have unintentional injury (17/20 v. 43/73, RR 1.4, 95\% CI 1.1-1.9). Three primary causes of trauma among Aboriginal Canadians accounted for more than $80 \%$ of cases (Table 1): motor vehicle crashes, impact by an object or animal, and falls or jumps.
Of Aboriginal Canadian trauma patients admitted to hospital, 25 (31\%) required admission to an intensive care unit and $48(59 \%)$ required at least 1 operation. Of the 93 Aboriginal Canadian trauma patients identified, 12 (13\%) died before arrival at a hospital and a further $2(2 \%)$ died after admission to hospital. Despite similar injury severity scores, the overall case-fatality rate of $15 \%$ among Aboriginal Canadian trauma patients was significantly lower than the $31 \%(531 / 1686 ; 344$ dead before arrival at hospital and 187 in-hospital deaths) observed in the reference population $(p<0.001)$. However, the population mortality was higher among Aboriginal Canadians (38.7 v. 21.6 per 100000 per year, RR 1.8, 95\% CI 1.0-3.0, $p=0.046$ ).

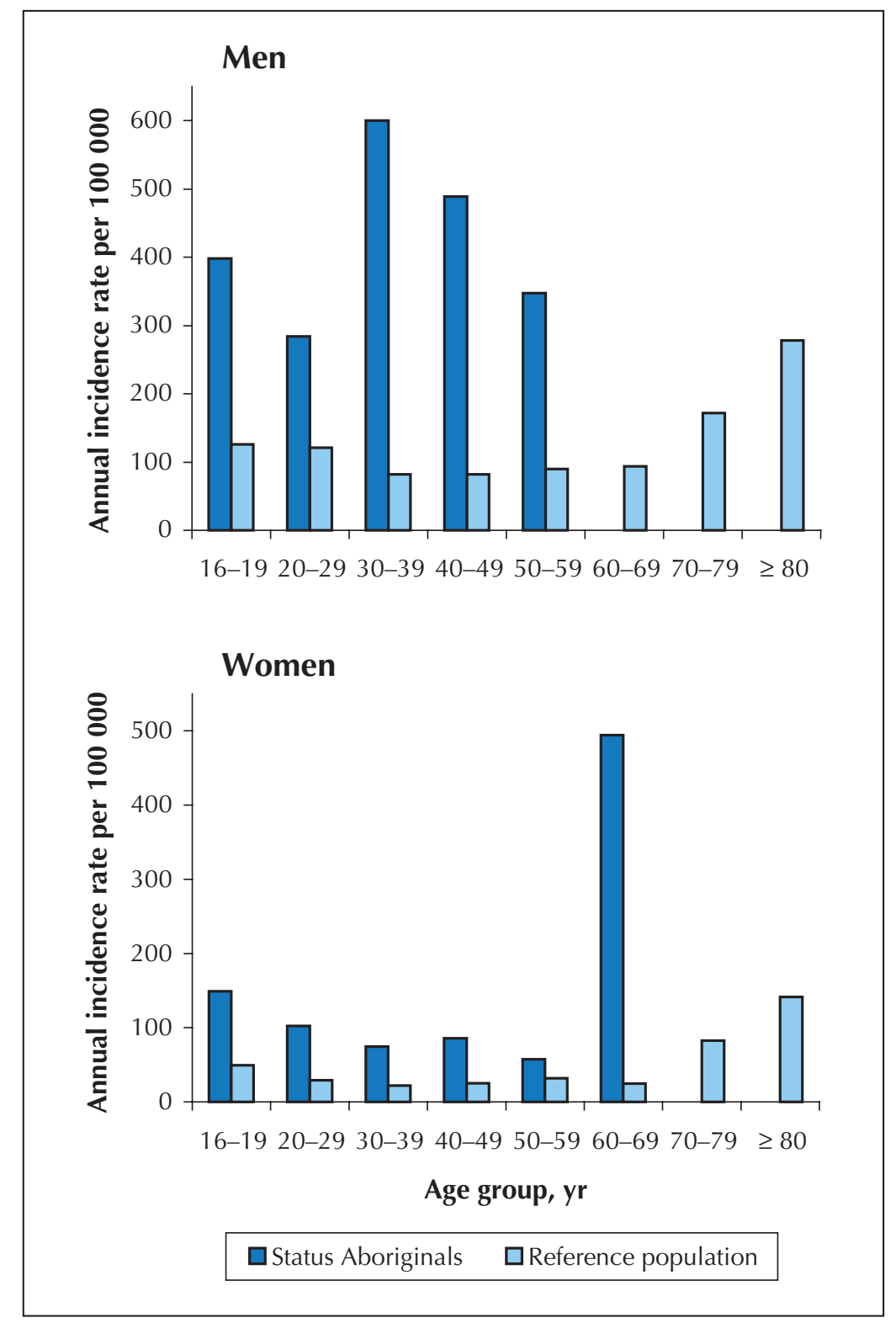

Fig. 2: Age-specific incidence in men and women of severe, multisystem injury (injury severity score $\geq 12$ ) among status Aboriginal Canadians and in the reference population in the Calgary Health Region, Calgary (Alta.), 1999-2002. 


\section{Interpretation}

We found that Aboriginal Canadians had nearly a 4-fold greater risk of severe trauma than the non-Aboriginal population. Motor vehicle crashes accounted for the overwhelming majority of cases of severe injury or death in both populations. Status Aboriginal Canadians were almost 5 times more likely than the reference population to be involved in such events. The possible explanations for this are intriguing and could involve any of the components of Haddon's matrix: ${ }^{9}$ environmental factors (e.g., road conditions on reserves), physical factors at the time of the event (e.g., vehicle maintenance, seatbelt use) and social factors (e.g., driving behaviours as a result of law enforcement practices against speeding, numbers of car occupants, lifestyles involving frequent highway travelling). It may be dangerous to attribute the higher numbers primarily to alcohol use (although this has been implied as an important factor in other studies ${ }^{10-15}$ ) since other potentially correctable factors may then not be investigated.

Aboriginal Canadians had a 10-fold greater risk of injury secondary to assault and a 3 -fold greater risk of traumatic suicide. It should be noted that the frequency of assault is underestimated by the entry criteria of the study: blunt and penetrating intentional injuries, although they may be lifethreatening, frequently cause single-system injury, and are therefore often not captured in trauma registries using injury severity scores of 12 or greater as a prerequisite for inclusion.

Although we found that Aboriginal Canadians had a higher population mortality due to trauma than the reference population, the case-fatality rate after severe trauma was significantly lower in the Aboriginal group despite similar injury severity scores between the groups. This apparent post-traumatic survival advantage may be accounted for

\section{Table 1: Primary causes of severe traumatic injury among status Aboriginal Canadians and in the reference population, 1999-2002}

\begin{tabular}{lccc}
\hline & \multicolumn{2}{c}{ No. of cases per 100000 per year } & \\
\cline { 2 - 3 } Primary cause & $\begin{array}{c}\text { Status Aboriginal } \\
\text { Canadians }\end{array}$ & $\begin{array}{c}\text { Reference } \\
\text { population }\end{array}$ & $\begin{array}{c}\text { Relative risk } \\
(95 \% \mathrm{Cl})\end{array}$ \\
\hline Impact by object or & $19(52.6)$ & $155(6.3)$ & $8.3(4.9-13.4)$ \\
animal & $6(16.6)$ & $62(2.5)$ & $6.6(2.3-15.1)$ \\
Stabbing or slashing & $47(130)$ & $663(27.0)$ & $4.8(3.5-6.5)$ \\
Motor vehicle crash & & & \\
Hanging or & $7(19.4)$ & $107(4.4)$ & $4.4(1.7-9.5)$ \\
asphyxiation & $2(5.5)$ & $40(1.6)$ & $3.4(0.4-13.1)$ \\
$\begin{array}{l}\text { Fire, explosion or } \\
\text { smoke inhalation }\end{array}$ & $12(33.2)$ & $537(21.9)$ & $1.5(0.8-2.7)$ \\
Fall or jump & 0 & $46(1.8)$ & - \\
Firearm related & 0 & $49(2)$ & - \\
Other & 0 & $27(1.1)$ & - \\
Environmental & $93(257.2)$ & $1686(68.8)$ & $3.7(3.0-4.6)$ \\
\hline All & & &
\end{tabular}

by the statistically significant age difference between the groups, although other factors are possible. It is worth pointing out that many Aboriginal Canadians may have survived the initial injury to live in their communities with significant and chronic sequelae of major trauma. Whether the needs of these patients are being adequately met is a potentially important area in health services research.

The little that is known about trauma among Aboriginal Canadians comes primarily from mortality data. ${ }^{16,17}$ Despite constituting only $5 \%$ of Alberta's population, Aboriginal Canadians accounted for $16 \%$ of people in Alberta who died of motor vehicle crash-related injuries in $2001 . .^{18}$ The incidence of death caused by motor vehicle crashes in Aboriginal communities is high compared with that in nonAboriginal communities (36 v. 11 per 100 000). ${ }^{18}$ Although these figures are disturbing, they provide only a glimpse of the problem: trauma-related morbidity, both acute and long-term, which can be devastating to individuals and to society, has not been well studied in Canada.

Our study has limitations. Métis and many non-status Aboriginal groups could not be identified using registered status as a proxy for ethnicity. In the case of subjects for whom no personal health care number could be found, the use of surnames for stratification was an imperfect methodology. Furthermore, this study fails to identify the relative incidence rates of nonsevere trauma. Taken together, these sources of underestimation provide a conservative view of the problem of trauma in Aboriginal Canadian groups. Finally, although the Alberta Trauma Registry collects data in a prospective fashion, its contribution to identifying socioeconomic factors, specific injury-related factors, comorbidities, complications, patient satisfaction and outcomes is necessarily limited.

A comprehensive, prospective surveillance strategy design that provides detailed information on the home address of trauma patients, where the trauma occurred, trauma scene characteristics, injury treatment and outcomes, provided by the Calgary Region 3 Aboriginal Community Health Council, has allowed new research priorities to be identified. Risk factors for severe trauma and the outcomes of Aboriginal Canadian victims of severe trauma need to be better understood to implement interventions that can reduce the burden of trauma in this population.

This article has been peer reviewed.

From the Departments of Surgery (Karmali, Harrop, Kirkpatrick, Kortbeek, Hameed), Critical Care Medicine (Laupland, Kirkpatrick, Winston, Kortbeek, Hameed), Medicine (Laupland) and Family Medicine (Crowshoe), University of Calgary, and Trauma Services, Calgary Health Region (Findlay, Kirkpatrick, Kortbeek, Hameed), Calgary, Alta.

Competing interests: None declared.

Contributors: Shahzeer Karmali, Robert Harrop, Andrew Kirkpatrick, Brent Winston, John Kortbeek, Lindsay Crowshoe and Morad Hameed contributed to the conception and design of the study. Kevin Laupland and Christi Findlay contributed to the acquisition and analysis of the data. All of the authors contributed to the interpretation of the data. Shahzeer Karmali, Kevin Laupland and Morad Hameed drafted the article. Robert Harrop, Christi Findlay, Andrew Kirkpatrick, Brent Winston, John Kortbeek and Lindsay Crowshoe provided critical revision for important intellectual content. All of the authors gave final approval of the article submitted. 
Acknowledgements: We thank Dr. Robert Mulloy, Dr. Stephen M. Cohn, Dianne Dyer and members of the Region 3 Aboriginal Community Health Council for their insights and guidance, and Donna Lentjes and the Centre for Health \& Policy Studies, University of Calgary, for providing financial support for the study.

\section{References}

1. Canadian Institute for Health Information. National trauma registry report Hospital injury admissions 1998/1999. Toronto: The Institute; 2001.

2. Facts on injury. Public Health Agency of Canada. Injury section. Available: www.phac-aspc.gc.ca/injury-bles/facts_e.html (accessed 2005 Feb 28).

3. MacMillan HL, MacMillan AB, Offord DR, Dingle JL. Aboriginal health CMA7 1996;155(11):1569-78.

4. Young TK. Review of research on Aboriginal populations in Canada: relevance to their health needs. $B M 7$ 2003;327(7412):419-22

5. Government of Canada. Indian Act. Ottawa: The Government of Canada; 1996. cat. No. YX76-I5/1996.

6. Alberta Health and Wellness. Available: www.health.gov.ab.ca/regions $/ \mathrm{maps} / \mathrm{r} 3$.pdf

7. Centre for Surveillance Coordination, Health Canada. Inventory of injury surveillance data sources and surveillance activities. Available: www2.itssti.hcsc.gc.ca/clf/CLFInventory.nsf/idview/040312101026-JP-T2?OpenDocument \&lang $=\mathrm{E}$ (accessed 2005 Feb 28).

8. Champion HR, Copes WS, Sacco WJ, Lawnick MM, Keast SL, Bain LW, et al. The Major Trauma Outcome Study: establishing national norms for trauma care. 7 Trauma 1990;30(11):1356-65.

9. Conroy C, Fowler J. The Haddon matrix: applying an epidemiologic research tool as a framework for death investigation. Am F Forensic Med Pathol 2000;21(4):339-42.

10. Blackmer J, Marshall SC. A comparison of traumatic brain injury in the Saskatchewan native North American and non-native North American populations. Brain Inj 1999;13(8):627-35.

11. Douglas M. Restriction of the hours of sale of alcohol in a small community: a beneficial impact. Aust N Z 7 Public Health 1998;22(6):714-9.

12. Berman M, Hull T, May P. Alcohol control and injury death in Alaska native communities: wet, damp and dry under Alaska's local option law. F Stud Alcohol 2000;61(2):311-9.

13. Landen MG, Beller M, Funk E, Propst M, Middaugh J, Moolenaar RL. Alcohol-related injury death and alcohol availability in remote Alaska. $7 A M A$ 1997;278(21):1755-8.

14. Li G, Smith GS, Baker SP. Drinking behavior in relation to cause of death among US adults. Am 7 Public Health 1994;84(9):1402-6.

15. Gallaher MM, Fleming DW, Berger LR, Sewell CM. Pedestrian and hypothermia deaths among native Americans in New Mexico: between bar and home. FAMA 1992;267(10):1345-8.

16. Mao Y, Morrison H, Semenciw R, Wigle D. Mortality on Canadian Indian reserves 1977-1982. Can 7 Public Health 1986;77(4):263-8.

17. Mao Y, Moloughney BW, Semenciw RM, Morrison HI. Indian reserve and registered Indian mortality in Canada. Can 7 Public Health 1992;83(5):350-3.

18. Sinnema J. Native traffic deaths skyrocket. Calgary Herald 2003 Apr 20;A12

Correspondence to: Dr. Morad Hameed, Trauma Services, Vancouver General Hospital, 855 West 12th Ave., Vancouver BC V5Z1M9; mhameed@vanhosp.bc.ca

\section{P HYSICIAN \\ MA N A G E R I NSTITUTE}

\section{A five level credit program exclusively for physicians designed to develop superior leadership and management skills}

Approved for RCPSC, CFPC, CCHSE credits

\section{In-house PMI}

A practical, cost effective and focused training opportunity held on-site for medical leaders and managers

For information:

tel $800663-7336$ or $613731-8610$ X2319 (PMI) or X2261 (In-house PMI) professional_development@cma.ca

\section{P M I S C H E D ULE}

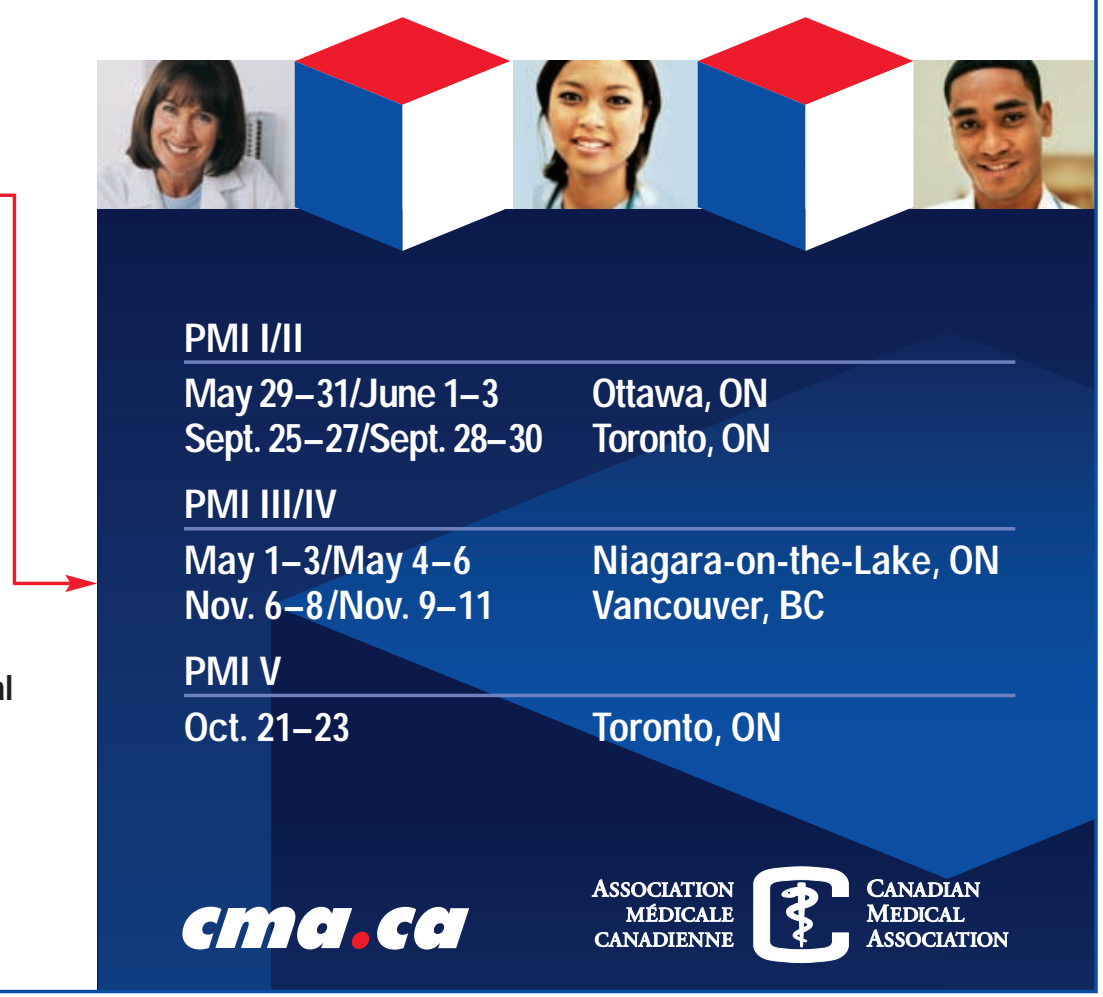

